\title{
Strategy for increasing the efficiency of the Russian economy under sanctions
}

\author{
Igor Ivanov $^{1 *}$ \\ ${ }^{1}$ Don State Technical University, Management and Business Technology Department, 344000 Ros- \\ tov-on-Don, Russian Federation
}

\begin{abstract}
The article offers a strategy for increasing the Russian economy through the rational use of the country's natural resources. As tools, it is offered to apply a functional approach to determine the critical functions of the system in order to generate additional income to improve the country's economy. A scheme for influencing the control system using the negative feedback method to improve the quality of the system is offered. New criteria are proposed for assessing the work of governors and ministers. For the implementation of the introduced innovative technologies, it is proposed to use funds from the excess profits of oil companies. Code JEL L20, M11, O11, O12, P11, C52, A20.
\end{abstract}

\section{Introduction}

Currently, the main source of export income in Russia is the sale of energy resources, which are practically not recovered. For example, in terms of oil production, we rank second in the world, but in terms of explored reserves, it is a modest 8th place, with a share of the top 10 countries of $0.54 \%$.

According to analysts' forecasts, existing profitable oil reserves in Russia will be completely depleted by 2039 , unless production is reduced or new profitable fields are discovered.

Therefore, the problem is how to effectively use these resources in order to raise the living standards of the country's population and ensure the effective development of the state, while reducing oil production in subsequent periods.

\section{Concept}

When developing this strategy, the FCA (functional cost analysis) and the TIPS system (the theory of inventive problem solving) are used [1,2].

The basis of the FSA is a functional approach. At the same time, it is necessary to determine the critical functions of the system and to develop methods influencing these functions in order to improve the considered system with minimal costs. When improving critical functions, it is advisable to use the TIPS system, on the basis of which it is necessary

\footnotetext{
* Corresponding author: igoriv740@yandex.ru
} 
to formulate technical contradictions in solving the problem. Analysis of technical contradictions allows you to find a rational solution to the problem.

Since the article sets a goal of a very high level, it is advisable to set a goal of a lower level, to find ways to solve it and then link it with a goal of a higher level.

With a systematic approach, it is advisable to represent this relationship in the form of an control system analogy with negative feedback. In this case, the correlation of changing criteria and subsequent indicators will take place.

\section{Results}

\subsection{Urgency}

At present, productivity of most domestic enterprises is 2.5 times lower than in the United States. Therefore, in order to achieve a competitive advantage of our products, it takes a significant amount of time and investment in the reconstruction of enterprises.

To improve the national economy, it is necessary to determine the possibility of obtaining resources for this purpose. The experience of global improvement of the economies of many highly developed countries (Japan, China, South Korea) shows that, despite the specific features, there is a general approach, which consists in attracting American capital together with new technologies. Moreover, due to effective growth and self-development, in some positions the technologies of these countries are beginning to compete with the American technologies on the basis of which they developed.

We cannot use this tested way for Russia at this time because of political differences, which have now reached the greatest magnitude in the entire post-war history of our state.

Therefore, it is necessary to find other ways to obtain significant funds to improve the economy of our country. To determine the potential source of income, let's analyse the export opportunities of Russia.

\subsection{Implementation options}

When using FCA to achieve this goal, it is necessary to determine the critical functions of the system so that the entire system can be improved with maximum effect at minimal cost.

At the same time, the existing calculation technologies are difficult to use; therefore, the method of analogies of highly developed countries is applicable.

Even with high technologies and developed economies, there is a process of constant improvement in the process of competition. As a result, new strategies are being developed, new technologies are being promoted and new businesses are being formed. Table 1 shows data on the correlation between GDP per capita and the number of startups in highly developed countries.

The table shows that for most of the highly developed countries, the ratio of the specific GDP to the number of startups differs insignificantly, i.e. there is a connection between the number of startups and GDP per capita. Therefore, to improve the Russian economy, it is necessary to increase the number of startups significantly [3].

In the author's opinion, a significant increase in the number of highly-efficient startups cannot be implemented only by administrative instructions. And we, with the existing low productivity, need to organize startups much more than in highly developed countries. On this purpose, it is necessary to change the psychological attitude and significantly increase the intellectual facilities of workers, which largely depend on the education system and the health of the population. Therefore, two processes can be taken as critical functions of the system: education and health care. 
Table 1. Correlation of GDP per capita and the number of startups per one million people in 2020 in the highly developed countries of the world.

\begin{tabular}{|c|c|c|c|c|}
\hline № & Country & $\begin{array}{c}\text { GDP per capita, } \\
\text { USD }\end{array}$ & $\begin{array}{c}\text { Number of startups } \\
\text { per one million } \\
\text { people 2020 . }\end{array}$ & $\begin{array}{c}\text { GDP per capita and the } \\
\text { number of startups per } \\
\text { one million people in } \\
2020 .\end{array}$ \\
\hline 1 & 2 & 3 & 4 & 5 \\
\hline 1. & Switzerland & 79407 & 1791 & 44.34 \\
\hline 2. & Singapore & 58830 & 1393 & 42.23 \\
\hline 3. & The USA & 55809 & 1211 & 46.08 \\
\hline 4. & Ireland & 79703 & 1186 & 67.2 \\
\hline 5. & The UK & 43688 & 1147 & 38.09 \\
\hline 6 & Israel & 35293 & 1146 & 47.77 \\
\hline 7. & Canada & 51589 & 1080 & 55.70 \\
\hline 8. & Finland & 49241 & 884 & 89.20 \\
\hline 9. & Belgium & 47541 & 533 & 95.07 \\
\hline 10. & Germany & 47628 & 501 & 106.75 \\
\hline 11. & The UAE & 41420 & 388 & 324.65 \\
\hline 12. & Russia & 12012 & 37 & \\
\hline
\end{tabular}

At the same time, in order to change these functions radically, it is necessary to increase their funding significantly, for work in these areas to be the most prestigious in the public sector of the economy. For this, it is necessary to ensure competitive selection and a differentiated remuneration process depending on the quality of work. In addition, the material base for the implementation of the process must meet the best international standards. The management of these processes should be carried out by persons who have passed an objective competitive selection, in which a top-bottom method is excluded. To implement the offered strategy, it is necessary to influence the management system in the regions of the country. For this purpose, to include changes in GDP per capita and the number of start-ups in the region as the main indicators of the governors' reports. At the same time, in order to implement this effectively, it is necessary to change the process of selecting governors as follows: each of the candidates for governors, together with his team, develops his own project, which indicates how GDP per capita will be increased in the region, what new technologies will be implemented and how to change the well-being of the local residents of the region.

This project is sent to the Russian Academy of Sciences, where it is studied and an objective review with a qualitative and quantitative assessment is made. Thus, each of the candidates will have their own project with an appreciation of the Russian Academy of Sciences. These materials must be published, which will enable voters to evaluate candidates objectively, regardless of party affiliation.

The resulting increase in GDP per capita due to the introduction of new technologies should have a subsidised taxation. The similar elections should be organised for the heads of cities and district administrations, but they should already receive appreciation of their 
projects from the branch institutes of the Russian Academy of Sciences. For all the heads of authorities, objective functional indicators should be established and monetary incentives should be linked to the quality of the indicators performed.

In the region authorities, it is necessary to establish a strategic development department, which should coordinate the processes of increasing GDP in the region. The department's activities should be based on the following systems: FCA, TIPS, collective methods of searching ideas and a system of coordination with universities, leading enterprises of the region, the Russian Academy of Sciences, the Higher School of Economics and other scientific institutions.

The first stage in the work of the strategic department will be establishing a bank for the development of the region and the main enterprises. To do this, each ministry in its industry prepares a list of such problems based on statistical data, as well as the FCA, with the identification of the critical functions of the system. The second stage is to find ideas for solving problems. This stage has several directions:

1. Conducting an open competition for solution of problems with the involvement of a wide range of participants, both from our country and from other countries. After the developed projects are classified and the best works are awarded, the conditions for setting up temporary creative teams and the conditions for external support for the implementation of startups are determined.

2. Conducting a brainstorming session to solve problems. For this purpose, specialists are invited both from the field of activity directly related to the problem, and from other fields. At the same time, the experience shows that the most effective solutions are offered by people who are indirectly related to this problem.

When conducting a brainstorming session, in order to obtain a significant synergetic effect, a number of requirements must be met:

- all participants in the brainstorming session must be very interested in solving the problem;

- all participants should have experience in solving similar problems in related industries;

- all participants must be of the same rank, i.e. the group should not have principals and subordinates (the author's experience in conducting brainstorming sessions at enterprises shows that if there are leaders of different ranks in the group, the synergetic effect is very low).

On selecting the participants, the ideas are ranked by voting with a score. As a result, the significance of each idea is collectively determined. This makes it possible to objectively assess the comparative effectiveness of each idea and determine the appropriate sequence of their implementation. After ranking, the validity of ideas and the possibility of obtaining patents for inventions, utility models or industrial standards are determined. At the same time, it is necessary to determine the authorship, which is sometimes difficult to accomplish, since ideas were collectively expressed and often another one was added.

3. Sending problems to special scientific institutions for the development of draft solutions. This direction has the greatest effect in solving global problems that require great expenses.

As a result of this activity, a good basis is formed for the implementation of startups with the aim of production turnout based on new technologies.

The product development diagram is shown in Figure 1. 


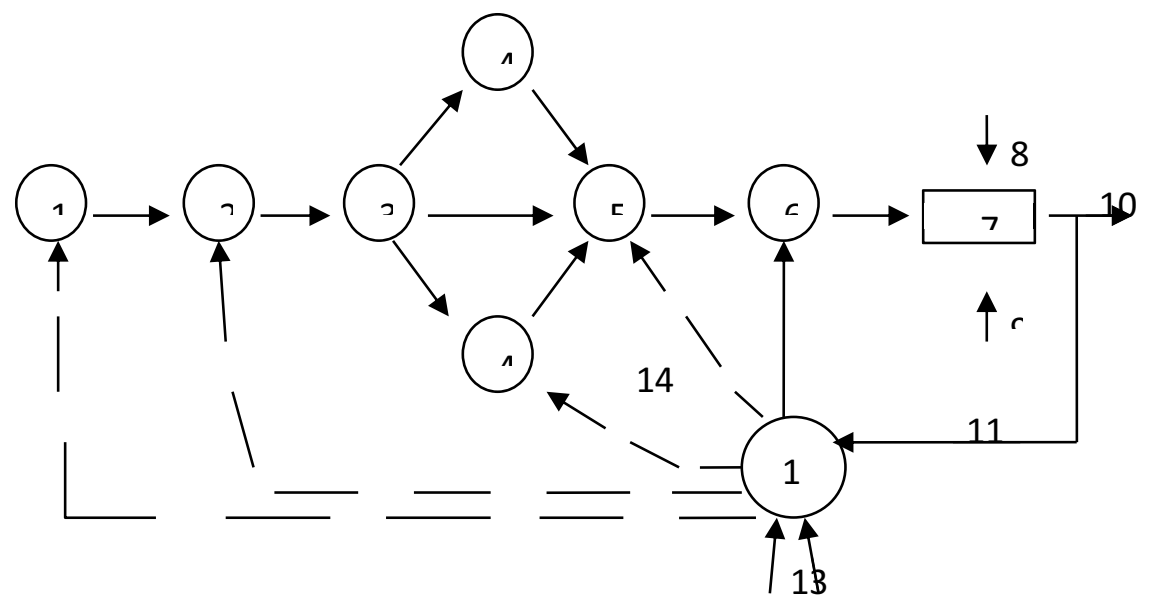

Fig. 1. The scheme of product development and improvement, based on the implementation of new technology for effective promotion to the market. 1-2 - development of functional indicators of the product; 2-3 - determination of the design parameters of the product; 3-4 - development of technical indicators of units; 4-5 development of a sketch design of the unit; 3-5 - development of technical conditions for the compositional connection of units; 7 - the process of making prototypes; 8 - external conditions of the production process (technical equipment, qualifications of specialists, premises, equipment, production conditions); 9 - all types of information that are used for the product manufacturing process (technical, economic and legislative); 10 - the process of sales of experimental products at the market; 11 - information about the sales process of prototypes and market conditions; 12 - the result of the process of analysing sales in comparison with sales of similar products from other firms (13), for the development of collective actions (14).

On the basis of this diagram, it is possible to analyse the process of manufacturing a product for sale at the market. Moreover, despite the peculiarities of setting up the production of various types of products, the basic laws of technology remain. The main feature of this scheme is a visual representation of the principle of negative feedback, which improves the quality of the product in the process of working out the design and technology of action. In this case, the feedback on elements $10,11,12,13$ forms a correcting action, which, depending on the deviation rate, can be locked with one of the following elements $(1,2,3,4,5,6)$. But, in the process of multiple repetitions, the quality of products will increase, which will make it possible to take a sustained position at the market. At the same time, with the investor, the terms of the contract for the manufacture of a significant amount of products are being developed and the regions where it can be effectively sold are determined. Regional leaders should arrange meetings for developers and potential investors to ensure the start-up is implemented. Alongside this, a team that has a common goal is being formed. The team often has 2 establishers, one of them is responsible for the technical part, and the other for its implementation.

Moreover, during the initial period, the main attention is paid to the prospect of market sales of the product. For this, prototypes and companies that produce similar products are analysed. It is necessary to determine the difference between the product being developed and other products of a similar purpose and the difference between the effect and the implementation. It is necessary to determine which companies are the world leaders in the production of similar products or technologies and display effective advantages of design and technology, also determine the prospect of market expansion in the future and the prospect of improving the design and technology.

At the nation-wide level, ministries also need to include the increase in GDP per capita due to the introduction of new technologies in the reporting standards. This will automatically 
affect the performance of qualitative indicators, which are normally great in number but difficult to quantify. For this purpose, it is necessary to establish regular reporting by ministers on the results of their work to the Duma, where one of the main indicators is increase in GDP per capita due to the introduction of new technologies, which will make it possible to assess the work of ministries and ministers quite objectively. At the same time, the system will turn out to be self-regulated, with a consequent increase in GDP per capita.

For the widespread use of students and university graduates in startups, it is necessary to modify the educational process significantly. For this, in addition to widely developed computer technology, it is necessary, for both technical and economic professions, to study FCA, TIPS, digital methods and breakthrough technologies that can be applied in various fields of activity.

It is necessary to modify the process of doing practical training so that representatives of the enterprise not only help students to collect materials on the operation of the enterprise, but also involve them in the processes of solving problematic issues in order to increase the efficiency of the enterprise.

Subsequently, the data obtained by students during practical training and enriched with theoretical material can be used as labour saving proposals, and further can be completed as scientific thesis and projects.

Recently, due to the COVID-19 pandemic, many problems of the existing health care system have been identified and government agencies have outlined ways to solve them. At the same time, experts noted that the main factor in counteracting infections is the body's own immunity.

It is known that immunity depends on many factors, the main of which are: genetics, nutrition, healthy lifestyle and prophylactic medicine. Currently, many national and foreign methods of recovery have been developed, but they are generally expensive and unaffordable to a wide scope of the population. At the same time, school-age children spend a lot of time using smartphones and computers, and due to this, there is a decrease in physical activity. And in the school curriculum, the number of hours for physical education remained the same as at a time when there were no smartphones and computers. As a result, more than half of schoolchildren wear glasses and have chronic illnesses.

Therefore, it is necessary, by means of using modern computer programs, to reduce the time for studying subjects of information technologies and to introduce additional special physical training lessons, given by teachers of health care systems, which have begun to be trained in some universities in Russia.

In addition, it is necessary to organise sports and health-related systems for various groups of the population, which will make it possible to get much healthier and will contribute to a more effective process of labor activity.

\subsection{Terms of sale}

To implement the offered system, it is necessary to determine the source of funding.

For this, we will use the TIPS system and compile technical contradictions (TC).

TC1. To improve the efficiency of the Russian economy under sanctions and during the pandemic, it is vital to develop and to introduce new, breakthrough technologies in education and medicine. To do this, it is necessary to increase massively the costs for these purposes, while the return on implementation might be revealed after a long period of time, and this attracts domestic and foreign investors to a lesser extent.

TC2. Financial means for modifying education and health care could be obtained in our country by increasing budgetary funding from other expenditure items.

$\mathrm{TC} 1$ is applicable to resolve contradictions, since it follows the goal in a greater degree. 
As a solution, it is necessary to introduce an additional tax for mineral resources in order to increase the efficiency of intellectual human capital for ensuring increase in GDP per capita in the future through the development and implementation of new technologies in various fields of activity. As a result, the welfare of the country will increase and the existing costs will be compensated for exceedingly. Moreover, the existing taxes, including the severance mineral industry tax must be left unchanged.

\subsection{Quantitative calculation}

In accordance with the data of the Annual Statistical Bulletin in 2020, Russia produced $10,625,000$ barrels of oil per day. We will take the cost of transporting and transhipping at $10 \%$ of the cost. Basing on IFRS (International Financial Reporting Standards) reporting for 2019 , the cost of oil production from Gazpromneft is $\$ 9.8$ per barrel, from Lukoil - $\$ 10.2$ per barrel and from Rosneft - \$ 11.3 per barrel. For the calculation $\$ 12$ per barrel is taken. The average oil price depends on many factors (economic, political, epidemiological). The average price of Russian Urais oil in 2019 was $\$ 63.59$ per barrel, and in 2020 - $\$ 41.73$ per barrel. The average is $\$ 52.66$ per barrel. We take into account $\$ 52$ per barrel. We believe that the proposed tax, let us denote it as Q, will amount to $10 \%$ of oil sales. 74 rubles are taken as dollar exchange rate.

\section{$\mathrm{Q}=10600000 * 0.9(52-12) * 365 * 0.1 * 74=1030701600000$ rubles}

In the 2021 budget, education spendings are $\$ 1.08$ trillion rubles, and Q is 1.03 trillion. rub. Thus, due to the supposed additional tax of oil-mining enterprises, it is possible to double the budget for education. This will allow, with an effective strategy, to increase the quality of innovation in various areas dramatically.

The profitability analysis of national and foreign oil mining enterprises shows that many of our enterprises have higher incomes in comparison with foreign ones. That is why an additional tax for the development of the national intellectual human capital will not reduce the competitiveness of domestic enterprises, but will only reduce the income of shareholders slightly and will require introducing more modern production and processing technologies.

For full implementation of this offer, it is necessary to change the budget rules on excess profits. Instead of the control price of excess income of $\$ 42.4$ per barrel, it is possible to set $\$ 52$ per barrel and the obtained excess profits from oil exports should not be included in the national welfare fund, but be transferred to the fund for the introduction of innovative technologies. This fund will be used to implement start-ups, primarily in the field of agricultural production, in order to effectively use the national natural resources [4-13], as well as in breakthrough technologies.

The features of breakthrough technologies are: 1) Lack of information about improvement of the product during technology development. That is why, it is necessary to apply new strategies and conduct parallel research. At the same time, breakthrough technologies provide significant advantages to those who implement them first; 2) The experience of specialists and the capabilities of the organisation do not have a special role, as the implementation of these technologies requires new skills and resources; 3) the successful application of breakthrough technologies is often carried out not due to technological breakthroughs, but due to a new composition of developed technologies, as a result of which new quality indicators are achieved and it ensures the efficiency of the system; 4) Disruptive technologies usually require large initial costs, but then they pay off through implementation in various areas of activity.

Currently, breakthrough multifunctional technology in the world is graphene technology [14]. In 2010, two of our compatriots Andrey Geim and Konstantin Novoselov, working in England, received the Nobel Prize for the discovery of graphene. Graphene is a twodimensional modification of carbon, in which atoms are combined into a hexagonal crystal 
pattern, and its gage is only one atom. It is the most electrically conductive, lightest and strongest version of carbon combination, it is more than 200 times firmer than steel.

When nanocarbon structures are included in a small amount into various environments, the physical properties of both solid and liquid environments change significantly. At the same time, the quality indicators of technical systems that can be applied in mechanical engineering, aircraft construction, steelmaking industry, construction, power engeneering, etc. are increasing. Graphene is effectively used in batteries, increasing the specific capacity of a lithium-ion battery by three times, which makes it possible to use them effectively in electric vehicles, and, in the future, in shunting locomotives and airplanes.

Currently, various laboratories around the world, also in Russia, are carrying out various studies to obtain nanocarbon compounds that are used in various technologies. TPK SINTEZ Ltd. has developed a technology for producing nanoparticles in microfluidic reactors, which make it possible to create controlled supercritical conditions for the synthesis of nanostructures. A mechanism was developed for the introduction of synthesized nanostructures into lubricants to clarify the possibility of improving their tribotechnical characteristics. For this purpose, research work on the topic: "Comparative tribological tests of lubricants after adding modifiers with different concentrations and after different technological modes of manufacture» was held. As a result of the modification of lubricants with nanoparticles, the wear rate is improved by $46 \%$, and the welding load rate is improved by $41 \%$, which shows the effectiveness of their use for increasing the duration of various types of transport and agricultural machines.

To improve the process of oil mining and processing technologies, it is advisable to use the disintegrator refinement system developed by the author with a gas turbine engine drive [15] and strengthening the disintegrator fingers with graphene, which will contribute to obtaining additional income from the oil refining process. To improve health care, it is offered to carry out a similar calculation of the amount of additional tax for the use of mineral resources due to the gas recovery and precious metals mining.

\section{Conclusion}

1) To improve the efficiency of the Russian economy, it is necessary, first of all, to improve the quality of education and health care by means of the introduction of innovative technologies, due to the introduction of an additional tax for the use of mineral resources, to ensure the growth of the intellectual human capital of Russia.

2) For implementing the offered strategy, to increase the creative part of education at schools and universities with a rating compensation of teachers for the quality of work.

3) To include the change in GDP per capita in the reporting indicators of the work of governors and ministers.

4) The obtained excess profits from oil exports should not be included in the national welfare fund, but transferred to the fund for the introduction of innovative technologies, which can be used to implement breakthrough technologies

\section{References}

1. I. Ivanov, E3S Web of Conferences, 135, 01089 (2019)

2. I. Ivanov, E3S Web of Conferences 210, 08013 (2020) DOI https://doi.org/10.1051/e3sconf/202021008013

3. N. Serbulova, et al., E3S Web Conf., 210, 02005 (2020) https://doi.org/10.1051/e3sconf/202021002005

4. A. lukhanyan, O. Panfilova, E3S Web of Conferences, 175, 13007 (2020) 
5. N. Serbulova, et al., IOP Conf. Ser.: Earth Environ. Sci., 403, 012127 (2019)

6. UNEP.Sustainable food systems programme (2018) http://web.unep.org/10yfp/programmes/sustainable-food- systems-programme

7. G. Spaargaren, P. Oosterveer, A. Loeber, Sustainability transitions in food consumption, retail and production. Food practices in transition: changing food consumption, retail and production in the age of reflexive modernity, 1-30 (2013) http://doi.org/10.4324/ 9780203135921

8. I. Avlasenko, L. Avlasenko, I. Peshkhoev, Y. Podkolzin, O. Savelyeva, E3S Web of Conferences, 175, 12006 (2020) doi.org/10.1051/e3sconf/202017512006

9. UN-ESCAP. Information and communications technology for food security and sustainable agriculture in the knowledge economy. (2008) http://www.unescap.org/sites/ default/files/CICT_1-E.pdf

10. I. Avlasenko, L. Avlasenko, I. Peshkhoev, Y. Podkolzin, O. Savelyeva, E3S Web of Conferences, 210, 130022020 (2020) doi.org/10.1051/e3sconf/202021013002

11. A. Balafoutis, B. Beck, S. Fountas, J. Vangeyte, T. Van Der Wal, I. Soto, Sustainability, 9 (2017) https://doi.org/ 10.3390/su9081339

12. A. McBratney, B. Whelan, T. Ancev, J. Bouma, Precision Agriculture, 6 (2005) https:// doi.org/10.1007/s11119-005-0681-8

13. G. Bora, J. Nowatzki, D. Roberts, Energy Sustainability and Society, 2 (2012) https://doi.org/10.1186/2192-0567-2-22

14. P. Sorokin, L. Chernozatonsky, UFN 183, 113-132 (2013) doi:10.3367/UFNr.0183.201302a.0113

15. I. Ivanov, I. Avlasenko, E3S Web of Conferences, 135, 6, 01090 (2019) 